\title{
Deriving a practical analytical-probabilistic method to size flood routing reservoirs
}

\author{
Matteo Balistrocchi*, Giovanna Grossi, Baldassare Bacchi \\ Hydraulic Engineering Research Group, Department of Civil Engineering, Architecture, Land Environment and Mathematics DICATAM, University of Brescia, I-25123 Brescia, Italy
}

\section{A R T I C L E I N F O}

\section{Article history:}

Received 7 December 2012

Received in revised form 18 September 2013

Accepted 26 September 2013

Available online 8 October 2013

\section{Keywords:}

Routing reservoir design

Derived distributions

Continuous simulations

Design storm methods

On-line reservoir

Off-line reservoir

\begin{abstract}
A B S T R A C T
In the engineering practice routing reservoir sizing is commonly performed by using the design storm method, although its effectiveness has been debated for a long time. Conversely, continuous simulations and direct statistical analyses of recorded hydrographs are considered more reliable and comprehensive, but are indeed complex or seldom practicable. In this paper a handier tool is provided by the analyticalprobabilistic approach to construct probability functions of peak discharges issuing from natural watersheds or routed through on-line and off-line reservoirs. A simplified routing scheme and a rainfall-runoff model based on a few essential hydrological parameters were implemented. To validate the proposed design methodology, on-line and off-line routing reservoirs were firstly sized by means of a conventional design storm method for a test watershed located in northern Italy. Their routing efficiencies were then estimated by both analytical-probabilistic models and benchmarking continuous simulations. Bearing in mind practical design purposes, adopted models evidenced a satisfactory consistency.
\end{abstract}

(C) 2013 Elsevier Ltd. All rights reserved.

\section{Introduction}

The flood routing practice presently involves a very wide range of application frameworks [49]. The most conventional one is the river flood control, in which extensive reservoirs must operate on a watershed scale. On the other hand, small storages supplied to perform on-site control have progressively gained a greater importance in sewer system planning, in order to mitigate the urbanization growth impact on the water cycle $[6,48,50]$. The range of possible design return periods therefore includes low values of 5:10 years, for the urban application scale, and higher values of 100:200 years, normally adopted for the watershed one [25].

Regardless of the demand of great versatility, the most popular sizing methods are still based on the traditional design storm approach $[5,48,52]$, which had previously been developed for the design of drainage canals. The possibility of effectively extending this straightforward methodology to the routing reservoir sizing has however undergone several critics so far $[1,38]$. In fact, such an approach is inevitably affected by conceptual deficiencies, which often lead to the device undersizing. Leaving apart concerns strictly related to catchment hydrological modelling, the most crucial ones are: (i) the inflow hydrograph return period equal to the depth-duration-frequency (ddf) curve one, (ii) the storage capacity

\footnotetext{
* Corresponding author. Tel.: +39 030 3715422; fax: +39 0303711312 .

E-mail address: matteo.balistrocchi@unibs.it (M. Balistrocchi).
}

completely empty at the flood occurrence, (iii) device performances evaluated with respect to a single return period.

The first topic refers to a general hypothesis, whose formulation is questionable independently of the application type. The runoff discharge is a precipitation driven process and depends on a multiparametric non-linear and non-stationary system. Indeed, hydrographs of various patterns can be derived from the same ddf curve or, conversely, lower return period ddf curves might produce more severe floods, when modelling arbitrary choices are changed [1]. In particular, the catchment initial condition strongly influences the runoff volume [35], so that several authors argue that it represents the most important factor in the routing reservoir sizing $[20,47]$. Additionally, a hydrograph features a number of characteristics: in this case the peak discharge, the flood volume and the flood duration should be accounted for [28,34,54]. Although moderately or strongly associated [21,33], these quantities commonly show different return periods within the same event. As a consequence, estimates derived by means of the design storm method are always biased.

The assumption of initially empty reservoir has been largely implemented in the construction of routing reservoir design methods [32]. Unfortunately, this is very restrictive for those devices with characteristic emptying times comparable to, or greater than, the catchment time of concentration. Some studies conducted in Mediterranean climates highlighted its relevance in the systematic undersizing of routing reservoir capacities [29,37,42] and stressed the need to evaluate the performance detriment due to the interaction with antecedent floods. 
Finally, the convenience of using multiple return periods, rather than a single return period, has already been underlined by Akan [4]: when a routing reservoir is sized according to a large return period, it generally performs poorly with respect to minor floods. On the contrary, if a small return period is employed, the device is ineffective during extreme events. Nonetheless, efficient routing reservoirs are expected to reduce peak discharges of floods having various sizes, temporal patterns and antecedent dry weather periods. This argument is directly connected to the environmental sustainability objectives introduced in the urban drainage system planning, by which any change in the natural hydrologic regime must be completely compensated [52].

On the other hand, the direct statistical analysis of extended flow discharge time series, in theory the most reliable approach, is possible only in very few cases, while indirect statistical methods, such as regional analyses, cannot be effectively exploited in small scale catchments. Deriving complete frequency distributions of the key hydrological variables certainly remains the most feasible manner to cope with design problems $[2,38]$. To this aim, continuous approaches, namely long term simulations and analytical-probabilistic methods, have been strongly advocated [3]. In particular, the analytical probabilistic approach appeared to be appealing to construct practical sizing methods: in fact, if the hydrological processes are represented by suitable functions, the derived probability distributions can be expressed by analytical relationships, as in the simplest design storm methods. With reference to the deficiencies previously examined, three advantages can be pointed out.

Firstly, although the involved physical phenomena are represented by using simple models, the derivation procedure is conceptually correct and the consequent estimation of the return period is more precise. The simplifying hypotheses regarding the precipitation process are however less restrictive than those of the design storm approach. Secondly, the performance estimation is sensitive to the real storm temporal sequence, since the antecedent dry weather period is involved in the rainfall statistical analysis. Thus, the flood overlapping probability can be properly evaluated, otherwise the initial emptying condition can be guaranteed on average through a suitable setting of the stochastic rainfall model parameters. Thirdly, the distribution of the rainfall variables are fitted according to the complete set of the observed events and the precipitation model is representative of a variety of storms changing in volume, duration and antecedent dry weather period.

In this work, probability distributions of catchment peak inflow discharges and peak outflow discharges, routed both by on-line and off-line routing reservoirs, were firstly developed. In Section 2 approximate models for the hydrological processes were implemented to achieve closed analytical forms for the derived distributions. Since the majority of the developed analytical-probabilistic models were employed to face urban drainage problems $[7,10,30,31,43]$, the possibility of extending the proposed methodology on a wider hydrological scale was herein tested. On-line and off-line routing reservoirs were sized in Section 3.1 for a smallmedium size natural catchment, located upstream the city of Brescia (Lombardy, North Italy). The main hydrological characteristics and an extended time series of rainfall data were known but no discharge record was available. Long-term continuous simulations were thus adopted as a benchmark. Discrepancies among performances assessed in Sections 3.2 and 3.3 were finally critically discussed in Section 3.4.

\section{The analytical-probabilistic method}

In the analytical-probabilistic method herein proposed, the design procedure is based on the derivation of the peak discharge cumulative distribution function (cdf) featuring the outflow of a routing reservoir. In accordance with the derived distribution theory, probability functions are constructed by assuming that the runoff variables depend on constituent rainfall variables through analytical relationships [3].

Their joint distribution functions are assessed with respect to samples of individual rainfalls, or storms, which are detected by separating the continuous time series of observed data into independent events. Although there is no definitive strategy [13], such a preliminary discretization plays a crucial role in ensuring the overall method reliability, because if the independence prerequisite is not met, the derived models could lead to unacceptable estimation errors [9].

This is an outcome of the strong sensitivity that the statistical properties of the input random variables show towards this procedure. As underlined by Dunkerley [23], a reviewer of a certain number of recent studies that exploited event based statistics, the applied discretization criterion must be reported to provide comprehensive information on the performed analysis. Hence, before deriving peak discharge cdfs, the identification of independent storms is discussed along with the precipitation probabilistic model and some adopted simplifications are justified.

\subsection{Identification of independent storms}

Various criteria have been established so far to identify independent storms. They can be classified into two basic categories: those exclusively focusing on the rainfall process and those matching the rainfall characteristics to the hydrological and hydraulic conditions of the catchment-device system [13]. Owing to its better potential to attain practical design objectives, a discretization procedure belonging to the second group was utilized in this study. Two discretization parameters were considered: an interevent time definition (IETD) and a rainfall volume threshold. Both of the values were chosen according to key hydrological properties of the catchment-device system.

The first quantity was introduced in hydrology by the fundamental paper by Restrepo-Posada and Eagleson [45] as the minimum rainless time between storms that is necessary to achieve a prescribed degree of independence. This time interval is directly applied to the continuous series: if two successive hyetographs are separated by a dry weather period shorter than the IETD, they are considered to be dependent. Therefore, they are merged into a single event, whose duration extends from the beginning of the previous one to the end of the following one, and whose volume amounts to the volume sum. On the contrary, they are identified as independent storms and maintained separated. Any isolated event is defined by three quantities: the rainfall volume, the wet weather duration and the antecedent dry weather period.

The event sample is then filtered by deleting those storms having a volume lower than the second threshold. When this occurs, the corresponding wet weather duration is interpreted as a dry weather period and joined to the adjacent ones. The reason for this additional parameter is to eliminate the negligible rainfalls that do not affect the estimation of the derived variable cdfs.

An operative manner to assess the IETD arises from recognizing a storm as independent if its effects on the considered hydrological phenomenon do not interfere with those due to any other storm. When dealing with wet weather discharges, this general criterion may be translated into a search for the minimum dry weather period that avoids the overlap of flood hydrographs. Consequently, the IETD value can be computed as the maximum travel time that is required for the runoff to reach the system outlet. This definition corresponds to that of the catchment time of concentration, which is supposed to account also for the emptying time of eventual storage capacities. 
The main attraction of this choice consists in the possibility of effectively coping with the troublesome problem of the system initial condition. The hypothesis that the drainage network and the routing reservoir are empty at the flood discharge onset is still herein adopted and actually holds. This significantly simplifies the derivation of the design variable distributions, because the input precipitation probabilistic model may only express the storm volume-wet weather duration joint distribution omitting that of the antecedent dry weather period.

Moreover, in this framework actual events are those that produce runoff, while very small rainfalls affect neither the flood frequency, nor the estimation of the routing reservoir efficiency. When these insignificant events are purged out of the rainfall time series, the probability of the runoff null event is zero. Conversely, if maintained, they would complicate the next derivation steps, which should include an atom of probability in the origin of the runoff volume cdf. Bearing in mind the CN-SCS model of the hydrological losses [51], the rainfall volume threshold was identified with the initial abstraction (IA), that is the first portion of the total rainfall completely lost at the beginning of the event, and estimated according to average soil and land cover characteristics of the watershed.

As noticed in various climates [7,23], the means of the three rainfall event variables show a sensibly linear increasing trend when IETD rises over 1:3 h. Analogous proportional behaviours are evidenced according to IA, if it is larger than a few millimetres [9]. Standard deviations also exhibit linear increasing behaviours with respect to both the discretization parameters.

In general, none of these sensitivities can be neglected because of the size of their variation ranges, which deeply affect the rainfall distribution calibration. The greater the discretization parameters, the larger the rainfall volumes and the longer the antecedent dry weather and the wet weather periods are. Consistently, the average annual event number diminishes. This explains the previously mentioned possibility to adapt the rainfall probabilistic model to the specific hydraulic application.

\subsection{Precipitation probabilistic model}

The joint probability function of the rainfall variables is herein set by using two key hypotheses: (i) the rainfall event variables are independent of each other, (ii) the marginal distributions are approximated by exponential functions. Such hypotheses are often adopted in order to achieve an analytical integration of the derived distributions, even if they are seldom supported by the empirical evidence. In fact, the storm volume and the wet weather duration usually show a significant concordant association and more complex functions than the exponential one are needed to suit the observed marginal distributions.

The joint probability density function $p_{V T}(v, t)$ is therefore written in Eq. (1), as the product of the exponential marginal densities $p_{V}(v)$ and $p_{T}(t)$ of the storm volume $v$ and the wet weather duration $t$, respectively.

$p_{V T(v, t)}= \begin{cases}p_{V(v)} p_{T(t)}=\frac{1}{\lambda \zeta} \exp \left[-\left(\frac{t}{\lambda}+\frac{v-\mathrm{IA}}{\zeta}\right)\right] & \text { for } v \geqslant \mathrm{IA} ; t \geqslant 0 \\ 0 & \text { elsewhere }\end{cases}$

In this equation $\zeta$ and $\lambda$ indicate the scale parameters that rule the distributions of $v$ and $t$, while the initial abstraction IA is introduced as the lower boundary of the runoff volume distribution, consistently with the discretization criterion.

\subsection{Peak inflow discharge distribution}

A considerable improvement in the analytical-probabilistic representation of flood frequencies has recently been achieved by Guo and Adams [30]. In spite of rainfall-runoff routing models previously employed $[19,22,24]$, these authors implemented in the derivation procedure the schematization of the discharge hydrographs suggested by Wycoff and Singh [53]. Owing to this solution, discharge characteristics, such as runoff peak discharge or volume, are related to the constituent precipitation variables by algebraic expressions. Closed-form analytical distributions were obtained both for the peak inflow discharge to a detention reservoir and for the outflow one [31].

In this derivation, the runoff volumes are estimated by applying a runoff coefficient $\Phi$ to the rainfall volume exceeding the initial abstraction IA. As demonstrated in previous works for urban catchments [10], although the model is extremely simple, it is able to mimic the natural decrease in the hydrological losses during a rainfall event. The runoff volume $v_{r}$ is then calculated by expression (2).

$v_{r}=\Phi(v-\mathrm{IA})$

The inflow hydrograph shape is then approximated to the triangle represented in Fig. 1: the height corresponds to the specific peak inflow discharge $q_{p i}$ and the base is given by the sum of the wet weather duration $t$ and the catchment time of concentration $t_{c}$, assumed to be a characteristic watershed constant parameter. This is indeed an additional simplifying hypothesis introduced in the derivation procedure. Nevertheless, investigating the effects of utilizing a variable time of concentration in analytical-probabilistic urban stormwater modelling rather than a constant one, Quader and Guo [43] concluded that the accuracy enhancement is trivial. In Fig. 1, the area bounded by the inflow hydrograph triangle represents the runoff volume (2), so that the $q_{p i}$ peak discharge is expressed with respect to the constituent rainfall variables as follows.

$q_{p i}=\frac{2 v_{r}}{t+t_{c}}=\frac{2 \Phi(v-\mathrm{IA})}{t+t_{c}}$

The peak inflow discharge $\operatorname{cdf} P_{\mathrm{Qpi}}$ may therefore be derived by using the non-exceedance probability (4).

$$
\begin{aligned}
P_{\mathrm{Qpi}\left(q_{p i}\right)} & =\operatorname{Prob}\left\{\frac{2 \Phi(v-\mathrm{IA})}{t+t_{c}} \leqslant q_{p i}\right\} \\
& =\operatorname{Prob}\left\{v \leqslant q_{p i} \frac{t+t_{c}}{2 \Phi}+\mathrm{IA}\right\} \text { and } v>\mathrm{IA}
\end{aligned}
$$

By intersecting the region defined by the inequality in (4) with the domain of definition of the probability density function (1), the domain of integration for applying the derived distribution theory is set. As illustrated in Fig. 2(a), this is a semi-infinite subset in random variable space contoured by linear boundaries, whose trapezoidal shape is almost identical for all possible choices of the hydrological model parameters. The non-exceedance probability (4) is accordingly computed by the integral (5).

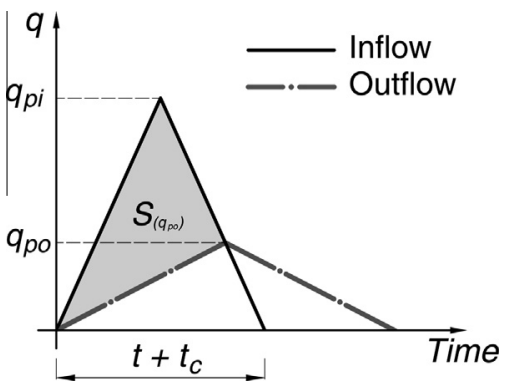

Fig. 1. Simplified hydrographs associated with the routing process: $q_{p i}$ peak inflow discharge, $q_{p o}$ peak outflow discharge, $t_{c}$ time of concentration, $t$ wet weather duration (adapted from Wycoff and Singh [53]). 
$P_{\mathrm{Q} p i\left(q_{p i}\right)}=\int_{0}^{\infty} \int_{\mathrm{IA}}^{q_{p i} \frac{\tau+t_{c}}{2 \Phi}+\mathrm{IA}} \frac{1}{\lambda \zeta} \exp \left[-\left(\frac{\tau}{\lambda}+\frac{v-\mathrm{IA}}{\zeta}\right)\right] \mathrm{d} v \mathrm{~d} \tau$

The analytical cdf of the peak inflow discharge rates is finally established by the relationship (6).

$P_{Q p i\left(q_{p i}\right)}=1-\frac{2 \Phi \zeta}{q_{p i} \lambda+2 \Phi \zeta} \exp \left[-\left(\frac{t_{c}}{2 \Phi \zeta} q_{p i}\right)\right]$

Since the exceedance probability of the null event $P_{\mathrm{Qpi}}(0)$ is zero, the average annual storm number $\theta_{s}$ corresponds exactly to the flood one $\theta_{f}$.

\subsection{Peak outflow discharge distribution for on-line reservoirs}

Dealing with an on-line routing reservoir, Fig. 3(a), the outflow discharge hydrograph may still be represented as a triangular hydrograph (Fig. 1), having height $q_{p o}$. The stored volume $S_{(Q p o)}$, which produces the routing of the runoff peak from $q_{p i}$ to $q_{p o}$, must satisfy the relationship (7).

$S_{\left(q_{p o}\right)}=\frac{1}{2}\left(q_{p i}-q_{p o}\right)\left(t+t_{c}\right)$

The derived distribution theory provides the definition of the nonexceedance probability function $P_{\mathrm{Qpo}}$ as shown in (8), in which expressions (2) and (7) are implemented.

$$
\begin{aligned}
P_{Q p o\left(q_{p o}\right)} & =\operatorname{Prob}\left\{2 \frac{\Phi(v-\mathrm{IA})-S_{\left(q_{p o}\right)}}{t+t_{c}} \leqslant q_{p o}\right\} \\
& =\operatorname{Prob}\left\{v \leqslant q_{p o} \frac{t+t_{c}}{2 \Phi}+\frac{S_{\left(q_{p o}\right)}}{\Phi}+\mathrm{IA}\right\}
\end{aligned}
$$

The stored volume $S_{\left(q_{p o}\right)}$ is itself a random variable depending on the event characteristics. Assuming its constancy is very restrictive and leads to overestimations of the routing efficiencies. This especially holds for major devices whose storage capacity is completely utilized only during extreme events. In general, the more severe the flood is, the greater the stored volume and the downstream peak discharge. Such a relationship is herein represented by using the conceptual model of the linear reservoir (9), in which $S_{\left(q_{p o}\right)}$ is proportional to the outlet discharge $q_{p o}$ through a storage constant $k_{S}$ [18].

$S_{\left(q_{p o}\right)}=k_{S} q_{p o}$

This constant can be assessed with regard to the routing reservoir hydraulic characteristics and has the important advantage of relying on both the storage and the outlet conveyance capacities. Consistently with the inequality in (8), expression (9) and the domain of definition in (1), the domain of integration of the peak routed discharge cdf is delimitated by the trapezoidal region illustrated in
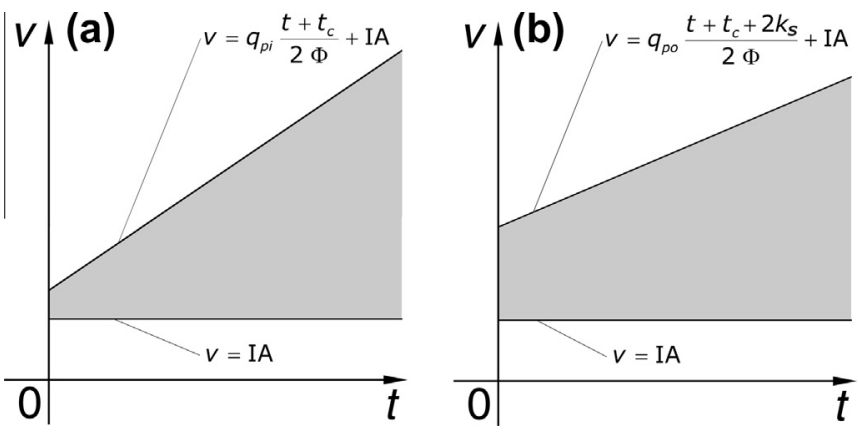

Fig. 2. Integration domain (grey filling) for deriving the peak inflow discharge distribution (a) and the peak outflow discharge distribution for on-line reservoirs (b).
Fig. 2(b). The integral that analytically defines the non-exceedance probability (8) is written in terms of Eq. (10).

$P_{\mathrm{Qpi}\left(q_{p i}\right)}=\int_{0}^{\infty} \int_{\mathrm{IA}}^{q_{p o} \frac{t+t_{c}+2 k_{s}}{2 \Phi}+\mathrm{IA}} \frac{1}{\lambda \zeta} \exp \left[-\left(\frac{\tau}{\lambda}+\frac{v-\mathrm{IA}}{\zeta}\right)\right] \mathrm{d} v \mathrm{~d} \tau$

The outflow peak discharge cdf $P_{\mathrm{Qpo}}$ is hence expressed by the probability distribution (11), which maintains the same structure of the inflow one (6), except for the insertion of the storage constant $k_{S}$ of the routing reservoir. Similar to the linear reservoir model, such a time may be interpreted as the average residence time of the runoff discharge into the routing reservoir. In this formulation, the characteristic time of the natural catchment-routing reservoir system is therefore given by the sum of the catchment time of concentration and double of the storage constant, approximating the maximum residence time of the runoff.

$P_{\mathrm{Qpo}\left(q_{p o}\right)}=1-\frac{2 \Phi \zeta}{q_{p o} \lambda+2 \Phi \zeta} \exp \left[-\left(\frac{t_{c}+2 k_{S}}{2 \Phi \zeta} q_{p o}\right)\right]$

\subsection{Peak outflow discharge distribution for off-line reservoirs}

When the storage capacity is supplied off-line as shown in Fig. 3(b), the routing scheme in Fig. 1 does not suit the real facility behaviour, because the inflow discharge is not routed until the diversion of the flood towards the routing reservoir begins. The threshold discharge of the weir $q_{s}$ must be accounted for in the probabilistic model.

Floods with peak discharges less than $q_{s}$ are not attenuated at all and the same cdf of the inflow discharge (6) must be employed for the routed one. Conversely, the incoming flow is split in the diverted flow, routed by the off-line routing reservoirs, and in the continuation flow. For practical purposes the weir hydraulics can be simplified by assuming that the continuation discharge is equal to the threshold discharge $q_{s}$ and the diverted discharge is equal to the exceeding part. That is, the diverted peak discharge $\left(q_{p i}-q_{s}\right)$ attenuates down to $\left(q_{p o}-q_{s}\right)$ and sums the threshold discharge $q_{s}$ downstream the device outlet. Likening the routing process of the diverted discharge to that of the total inflow in the on-line system, the expression of distribution (11) can be exploited for the distribution of the peak $\left(q_{p o}-q_{s}\right)$ released through the reservoir outlet.

Since the cdf of $\left(q_{p o}-q_{s}\right)$ does not exist for total routed discharges $q_{p o}$ less than $q_{s}$, its behaviour formally matches a censored random variable cdf. In this case, the probability that the random variable is included in the censored range equals the non-exceedance probability of the threshold discharge $q_{s}$, which is easily estimated by the peak inflow discharge cdf (6), as shown in (12).

$P_{Q s}=P_{Q p i\left(q_{s}\right)}=1-\frac{2 \Phi \zeta}{q_{s} \lambda+2 \Phi \zeta} \exp \left[-\left(\frac{t_{c}}{2 \Phi \zeta} q_{s}\right)\right]$

The peak outflow discharge cdf $P_{\mathrm{Qpo}}$ is thus summarized in the distribution (13), in which the formulation of cdf (6) is exploited to represent the non-exceedance probability of the non-routed portion of the total discharge.

$$
P_{Q p o\left(q_{p o}\right)}= \begin{cases}1-\frac{2 \Phi \zeta}{q_{p o} \lambda+2 \Phi \zeta} \exp \left[-\left(\frac{q_{p o} t_{c}}{2 \Phi \zeta \zeta}\right)\right] & \text { if } q_{p o} \leqslant q_{s} \\ P_{Q s}+\left(1-P_{Q s}\right)\left\{1-\frac{2 \Phi \zeta}{\left(q_{p o}-q_{s}\right) \lambda+2 \Phi \zeta} \exp \left[-\frac{t_{c}+2 k_{s}}{2 \Phi \zeta}\left(q_{p o}-q_{s}\right)\right]\right\} & \text { if } q_{p o}>q_{s}\end{cases}
$$

\section{Case study}

In order to test the possibility of applying the analytical-probabilistic methodology to spatial scales greater than those of urban catchments, the upstream Garza watershed was selected as a case 

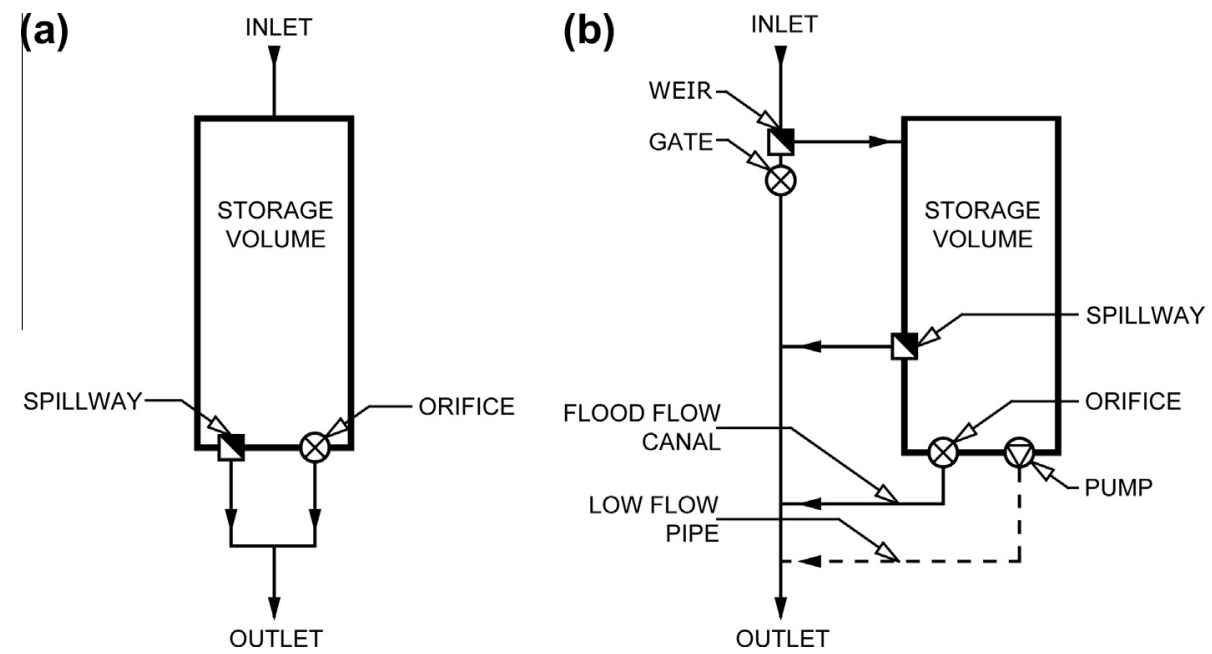

Fig. 3. Connection scheme of the storage volume to the stream riverbed (a) on-line (b) off-line.

study. This is a natural reach whose catchment area belongs to the southern edge of the central Alpine foothills (Lombardy, Italy) (lower-right box in Fig. 4).

After an upstream stretch with very steep slopes, the stream enters the higher Padan Plain where it immediately crosses the strongly urbanized northern outskirts of the city of Brescia. Here its river bed is often constrained into culverts or narrow canals with insufficient conveyance capacity, while original floodplains are now covered by industrial and residential settlements. A routing reservoir could therefore be a viable solution to mitigate the unacceptably high flooding risk, since a suitable location can be identified in the valley bottom a few kilometres upstream the urban area. The selected outlet delimitates a mainly natural catchment (Fig. 4), whose morphometric parameters, assessed through a terrain analysis of a $20 \mathrm{~m}$ resolution DEM, are listed in Table 1.

As proposed by Giandotti [27], who analysed a number of natural floods in Italy, the time of concentration $t_{c}(\mathrm{~h})$ can be estimated by the empirical relationship (14) as a function of the catchment area $A\left(\mathrm{~km}^{2}\right)$, the main reach length $L(\mathrm{~km})$ and the elevation drop, expressed as the difference between the average elevation $H_{\text {ave }}$ (m a.s.l.) and the minimum elevation $H_{\min }$ (m a.s.l.)

$t_{c}=\frac{4 \sqrt{A}+1.5 L}{0.8 \sqrt{H_{\text {ave }}-H_{\text {min }}}}$

The infiltration capacity is moderately low and soils can be averagely classified in hydrologic group $\mathrm{C}$, according to the CN-SCS method [51]. The land cover consists in woods in the upstream catchment which are progressively substituted by agricultural fields surrounded by residential and industrial areas in the valley bottom.

The $\mathrm{CN}$ value is reported in Table 1, along with the soil moisture deficit at the time runoff begins $S$ and the initial abstraction IA. Their values were evaluated by using standard $\mathrm{CN}-\mathrm{SCS}$ criteria for the average moisture condition AMC II.

The watershed precipitation regime is sub-alpine with two maxima, spring and autumn, and two minima, winter and summer, while the annual average rainfall volume is about $1000 \mathrm{~mm}$. During summer, short duration and high intensity storms separated by long dry weather periods occur. On the contrary, longer but less intense precipitations feature the wet seasons.

The meteorological input to the different procedures was represented by a 45 year long time series of rainfall observations recorded every $30 \mathrm{~min}$ at the ITAS Pastori raingauge (1949-1993), located in Brescia, a few kilometres south of the watershed.

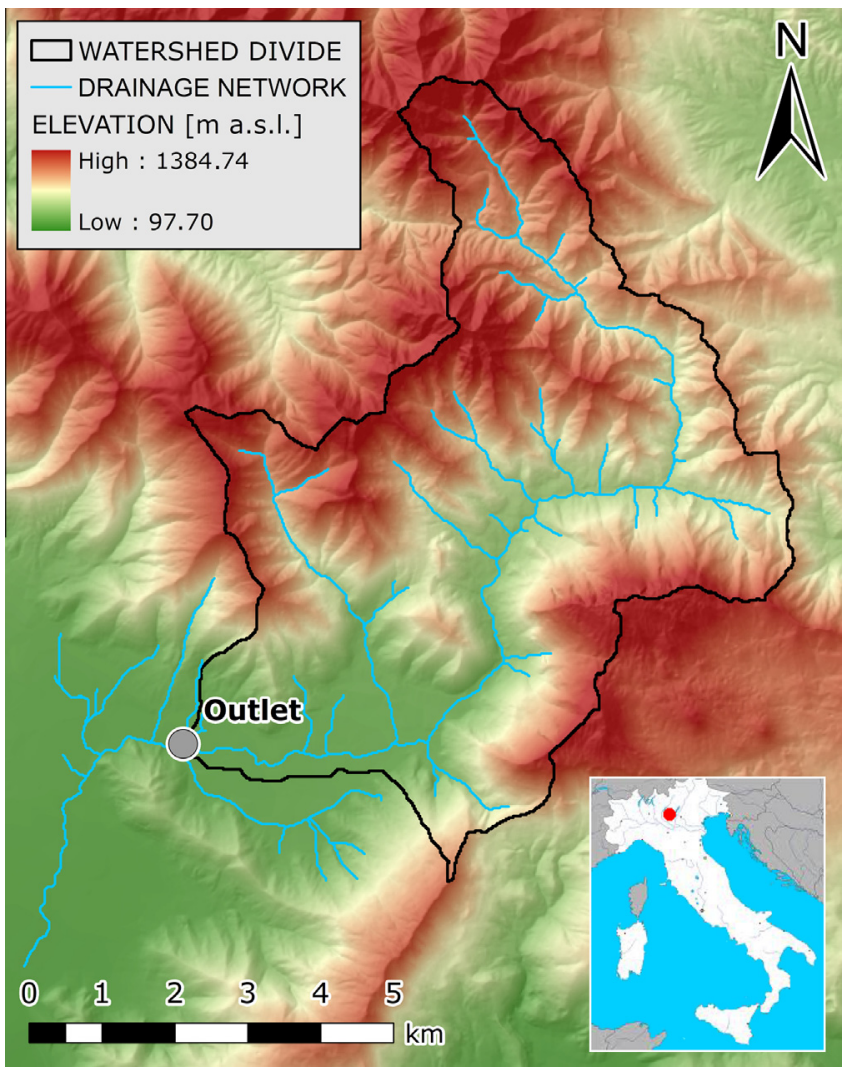

Fig. 4. Digital Elevation Model of the Garza stream catchment and outlet location.

\subsection{Reservoir sizing by the design storm method}

The design storm method was firstly based on a lumped hydrological model to derive inflow hydrographs for varying return periods. In the Italian hydrologic practice, ddf curves are usually expressed as simple monomial relationships (15), whose parameters $a\left(\mathrm{~mm} / \mathrm{h}^{n}\right)$ and $n$ generally depend on the return period $T$ (years).

$v_{(t, T)}=a_{(T)} t^{n_{(T)}}$

When the rainfall volume variability shows empirical scaling properties [14] and is suitably represented by Gumbel distributions for 
Table 1

Main hydrological characteristics of the Garza watershed.

\begin{tabular}{llllllll}
\hline $\begin{array}{l}A \\
{\left[\mathrm{~km}^{2}\right]}\end{array}$ & $\begin{array}{l}L \\
{[\mathrm{~km}]}\end{array}$ & $\begin{array}{l}H_{\text {ave }} \\
{[\mathrm{m} \text { a.s.l. }]}\end{array}$ & $\begin{array}{l}H_{\min } \\
{[\mathrm{m} \text { a.s.l. }]}\end{array}$ & $\begin{array}{l}t_{c} \\
{[\mathrm{~h}]}\end{array}$ & $\mathrm{CN}$ & $\begin{array}{l}S \\
{[\mathrm{~mm}]}\end{array}$ & $\begin{array}{l}\mathrm{IA} \\
{[\mathrm{mm}]}\end{array}$ \\
\hline 44.6 & 15.5 & 619.9 & 195.0 & 3.00 & 75 & 84 & 17 \\
\hline
\end{tabular}

any of the durations, as in this case, Eq. (15) can be written in the terms of Eq. (16) [44].

$v_{(t, T)}=v_{1}\left\{1-\frac{\overline{C V}}{1.283}\left[0.5772+\ln \left(\ln \left(\frac{T}{T-1}\right)\right)\right]\right\} t^{n}$

In this formulation exponent $n$ is the time scale parameter and coefficient $a$ is directly expressed as a function of the return period $T$ by two sample statistics: $\overline{C V}$ is the mean variation coefficient of the maximum annual rainfall volume samples recorded for different durations $t(\mathrm{~h})$ (usually in Italy observations refer to $1 \mathrm{~h}, 3 \mathrm{~h}, 6 \mathrm{~h}$, $12 \mathrm{~h}$ and $24 \mathrm{~h}$ ), while $v_{1}(\mathrm{~mm})$ is the mean maximum annual hourly rainfall volume. Ddf parameter values estimated for the Brescia raingauge are: $n=0.33, \overline{C V}=0.36$ and $v_{1}=28.3 \mathrm{~mm}$.

The point precipitation was converted into areal precipitation by the areal reduction factor $r$ (17) proposed by Moisello and Papiri [40] for storms that occur in the North of Italy, when the catchment area $A\left(\mathrm{~km}^{2}\right)$ ranges between 5 and $800 \mathrm{~km}^{2}$ and the duration $t$ between 0.15 and $12 \mathrm{~h}$.

$r_{(A, T)}=1-\exp \left[-2.472 A^{-0.242} t^{0.6-\exp \left(-0.643 A^{0.235}\right)}\right]$

The design rainfall pattern was then developed according to the Chicago method [5], by setting the wet weather duration equal to twice the catchment time of concentration. This choice was intended to match two opposite design targets: on one hand, to have a significant flood volume, on the other hand, to maintain high peak discharges. Since the area reduction factor (17) depends on the wet weather duration and the intensity varies during the event, rainfall volumes for partial durations were deduced from the areal ddf curve, given by the product of (16) and (17), so that higher intensities were reduced more than the lower ones.

Hydrological losses were computed by means of the CN-SCS procedure under average antecedent moisture conditions (AMC II), since the other conditions AMC I and AMC III are considered to yield unreasonably large, or low, runoff volumes when applied within a design storm procedure. Such arbitrary choices are driven by the practical experience gained in several designs and researches carried out in the climatic-hydrological context of the Padan Plain by some authors [12,15,26,36].

The rainfall excess was finally routed by a Nash conceptual scheme [41] consisting of two linear reservoirs to obtain the outlet discharge. The storage constant $k_{N}$ was assessed through Eq. (18), that originates from a similitude between the instantaneous unitary hydrograph peak of the Nash method and that of the kinematic method, if a triangular shape is assumed [8]. In such an equation, $n_{i}$ is the number of reservoirs, $\Gamma$ (.) the complete gamma function and $t_{c}$ the catchment time of concentration given by Eq. (14).

$k_{N}=\frac{\left(n_{i}-1\right)^{n_{i}-1} e^{-\left(n_{i}-1\right)}}{2 \Gamma\left(n_{i}\right)} t_{c}$

According to Akan [4], various design hydrographs related to return periods rising from 5 years to 100 years were derived and utilized as inflow to simulate the reservoir behaviour. To do so, hydraulic models of the routing reservoirs were developed for the connection scheme illustrated in Fig. 3(a), for the on-line case, and in Fig. 3(b), for the off-line one.
In the former, an embankment crossing the stream bed and directly intercepting the natural flow is employed to delimitate an open pond. Outlet orifices and a spillway were set to provide an increasing discharge capacity with the water stage. In the latter, the stream flow is diverted into an analogous open pond by a side weir combined with a gate. The captured runoff is discharged towards the downstream reach by orifices, a spillway and a pump system, to facilitate the emptying process for very low stages. Storage capacities and outlet discharge curves were defined by a trial process in which they were changed step by step to obtain a desired routing efficiency, defined as in expression (19). In consideration of the different levels of effectiveness achievable by on-line and off-line solutions, target values were set to about $20 \%$ and $30 \%$, respectively.

$\eta=\frac{q_{p i}-q_{p o}}{q_{p i}}$

The storage capacity was finally evaluated in $400,000 \mathrm{~m}^{3}$ for both the connection types, the threshold discharge $q_{s}$ in $45 \mathrm{~m}^{3} / \mathrm{s}$, and the reservoir storage constants $k_{S}$ were established in $1.1 \mathrm{~h}$, for the on-line reservoir, and in $3.1 \mathrm{~h}$, for the off-line one. Storage constants were estimated as the ratio between the storage capacity and the outlet discharge corresponding to the filling condition. With reference to the previously defined variables, Table 2 reports a synthesis of the hydrologic balances and the routing efficiencies assessed for the analysed return periods. As can be seen, target efficiencies are fairly uniform for return periods of practical interest, in the on-line case, and for peak rates significantly larger than threshold $q_{s}$, in the off-line one.

\subsection{Performance assessment by continuous simulations}

Continuous simulations of the rainfall-runoff transformation and routing processes occurring in the catchment-reservoir system were performed by means of the previously described model, in which the observed precipitation time series was employed as meteorological input. Some adaptations were however necessary to pass from the event based analysis to the continuous simulation.

Firstly, the reduction of the point precipitation to the area was obtained through variable factors inside the same storm by considering greater durations centred on the peak intensities. Secondly, the CN-SCS method can be implemented in this kind of modelling if the AMC variability and the catchment moisture decay during antecedent dry weather periods are properly accounted for [39]. Hence, during such periods, $\mathrm{CN}$ values were updated with regard to the conventional antecedent precipitation index $\mathrm{API}_{5}$ and seasonal AMC thresholds, while the residual moisture at the rainfall end was completely depleted within five days by an exponential function.

The three simulation outputs were statistically analysed through individual event statistics (IES), that is, the continuous series were separated in independent floods, detecting their peak flow rates and counting their average annual number $\theta_{f}$. In order to ensure the consistency with the analytical-probabilistic model, minimum times between floods utilized for separating the discharge series were equal to IETDs adopted for fitting the corresponding probability functions. Thus, the experimental return period $T$ was estimated by the relationship (20), where $F_{Q p}$ is the Weibull plotting position of the peak discharges.

$T=\frac{1}{\theta_{f}\left(1-F_{Q p}\right)}$

The more conventional formulation based on the maximum annual statistics actually gives matching results when the return period is greater than 10:20 years. However, this estimate is conceptually 
Table 2

Main hydrologic characteristics of the design storm events employed to size the online $^{\dagger}$ and the off-line* reservoirs.

\begin{tabular}{cllllllll}
\hline $\begin{array}{l}T \\
\text { [years] }\end{array}$ & $\begin{array}{l}v \\
{[\mathrm{~mm}]}\end{array}$ & $\begin{array}{l}\text { IA } \\
{[\mathrm{mm}]}\end{array}$ & $\Phi$ & $\begin{array}{l}q_{p i} \\
{\left[\mathrm{~m}^{3} / \mathrm{s}\right]}\end{array}$ & $\begin{array}{c}q_{p o}{ }^{\dagger} \\
{\left[\mathrm{m}^{3} / \mathrm{s}\right]}\end{array}$ & $\begin{array}{l}\eta^{\dagger} \\
{[\%]}\end{array}$ & $\begin{array}{l}q_{p o}{ }^{*} \\
{\left[\mathrm{~m}^{3} / \mathrm{s}\right]}\end{array}$ & $\begin{array}{l}\eta^{*} \\
{[\%]}\end{array}$ \\
\hline 2 & 41.5 & 17 & 0.23 & 16.7 & 13.7 & 17.9 & 16.7 & - \\
5 & 55.6 & 17 & 0.31 & 37.7 & 28.5 & 24.4 & 37.7 & - \\
10 & 64.9 & 17 & 0.36 & 55.6 & 43.4 & 22.0 & 46.1 & 17.1 \\
20 & 73.8 & 17 & 0.40 & 75.3 & 60.1 & 20.1 & 51.6 & 31.5 \\
50 & 85.3 & 17 & 0.45 & 103.6 & 82.3 & 20.6 & 70.6 & 31.9 \\
100 & 93.9 & 17 & 0.48 & 126.6 & 103.8 & 18.0 & 89.4 & 29.4 \\
\hline
\end{tabular}

more correct and should be more reliable for the lower return periods.

\subsection{Performance assessment by the analytical-probabilistic model}

The precipitation time series was separated into independent events by the discretization thresholds IETD and IA. Because of the physical meaning herein attributed, IETDs of $3 \mathrm{~h}, 4 \mathrm{~h}$ and $6 \mathrm{~h}$ were taken into consideration for the inflow discharge, the outflow routed by an on-line reservoir and the outflow routed by an off-line reservoir, respectively. The first value was assumed equal to the catchment time of concentration $t_{c}$, while the others were computed as the sum of this quantity and the storage constant $k_{S}$, considered to be the index of the average residence time of the stored runoff. By this choice, the initial condition of a totally empty storage capacity, implicit in the routing scheme of Wycoff and Singh [53] implemented in the derivation procedure, is mostly satisfied when an independent event occurs.

In this formulation the volume threshold of the discretization procedure must be equal to the initial abstraction of the simplified hydrologic loss model (2). In addition, the analytical-probabilistic approach must operate in average conditions. Therefore, the threshold IA was set equal to $17 \mathrm{~mm}$, corresponding to AMC II, Table 1 . Indeed, because of its large value, the latter parameter demonstrated to be dominating in the calibration of the derived cdfs, so that variations in the IETD setting were not particularly relevant.

The scale parameters of the joint probability density function $p_{V T}$ (1) were then assessed through the maximum likelihood criterion from the independent event samples, obtaining $16.8 \mathrm{~mm}$ for $\zeta$ and $19.8 \mathrm{~h}$ for $\lambda$. The average annual number of storms $\theta_{s}$, required to convert non-exceedance probabilities (6), (11), and (13) in return periods by equations analogous to (19), was estimated as well.

However, as expected, the parameter with respect to which all derived distributions proved to be more sensitive was the average runoff coefficient $\Phi$ of Eq. (2). Since the main objective of this work was to evaluate the discrepancies between continuous approaches, their maximum consistency had to be ensured. Thus, the average runoff coefficient was computed through hydrological simulations: for every individual event the actual losses due to the initial abstraction and to the following infiltration were distinguished and the corresponding runoff volumes were determined. By inverting Eq. (2) and knowing the rainfall volumes, individual event runoff coefficients were calculated and an average value of 0.32 was obtained.

\subsection{Result and discussion}

The initial evaluation was aimed at verifying if the average annual number of floods $\theta_{f}$ and storms $\theta_{s}$ are equal. In fact, because of the adopted discretization criterion, all independent storms are runoff producing and consequently cause a flood. As auspicated, matching outcomes were obtained: a number of 4:6 floods per years were deduced for the defined IETD range. Such values were considered to be reasonable for the flow regime of this kind of natural catchment.

The frequency distributions of the peak inflow discharge $q_{p i}$ developed through continuous approaches are represented in Fig. 5(a), along with the peak discharges derived by the design storm method. An overall satisfactory agreement is evidenced between the analytical-probabilistic curve and the continuous simulation statistics, especially when the return period $T$ is more than 2 years. In the interval 1:2 years, which is of little concern even for the smallest spatial scales of urban applications, discrepancies consist in an overestimation of the peak discharges.

The observation of the distribution graphs in Fig. 5(b) and (c) yield analogous considerations for the peak outflow discharges routed through the on-line and the off-line reservoirs. The effectiveness both of the derived model formulation and of the calibration criteria is therefore sustained. In particular, (i) the implementation of a variable stored volume in spite of a constant storage capacity proved to be extremely important to avoid performance overestimations of the on-line reservoir when the return period ranged between 5:20 years, (ii) the introduction of the non-exceedance probability $P_{\mathrm{Qs}}$ constrain is crucial to fit the general behaviour of the off-line reservoir over discharge $q_{s}$.

In view of various simplifications introduced in the analyticalprobabilistic model derivation, some aspects deserve to be detailed:

- In Mediterranean precipitation regimes, samples of individual event volume and duration exhibit probability distributions different from the exponential one, herein adopted. The exponential distribution may be interpreted as a particular case of the Weibull distribution, when the shape parameter is set to one. In the selected case study, the shape parameter is estimated in 0.92:0.98 and 1.20:1.40 for volume and duration, respectively. Even if such values are quite close to unity, the exponential assumption is rejected if confidence boundary tests are performed even adopting low significance levels; this is a common occurrence for the majority of the discretization parameter sets (in this respect a broader discussion can be found in [11]). Discrepancies mainly involve low volume-events: in this case the non-exceedance probability of the event volume is underestimated, while the non-exceedance probability of the event duration is overestimated. Moreover, neglecting the association between volume and duration should generally lead to improper increases in the estimates of the mean and the variance of the dependent variables. However, owing to the upper tail dependence property shown by observed sample data, the variation between the empirical copula and the independence one is expected to be larger for extreme storms. In fact, volume and duration demonstrate to be more strongly associated in this situation than in the ordinary one. The employed precipitation model is therefore meaningful only with reference to this kind of approach, where the dependent variable is issued from a ratio of the independent variables and a compensation of separate errors evidently occurs. Conversely, it does not have a general validity when dealing with the rainfall point process.

- The runoff coefficient is assumed constant in the derivation procedure, even if there is evidence that it shows an increasing trend according to the return period, both in natural and in urban catchments. In this formulation it is however applied to the rainfall volume exceeding an initial abstraction, whose relative importance decreases with the total event volume and the return period. The overall runoff volume-rainfall volume ratio is therefore greater for extreme storms. Nonetheless, when a very large range of return periods is examined, accounting for this dependency could be necessary. 

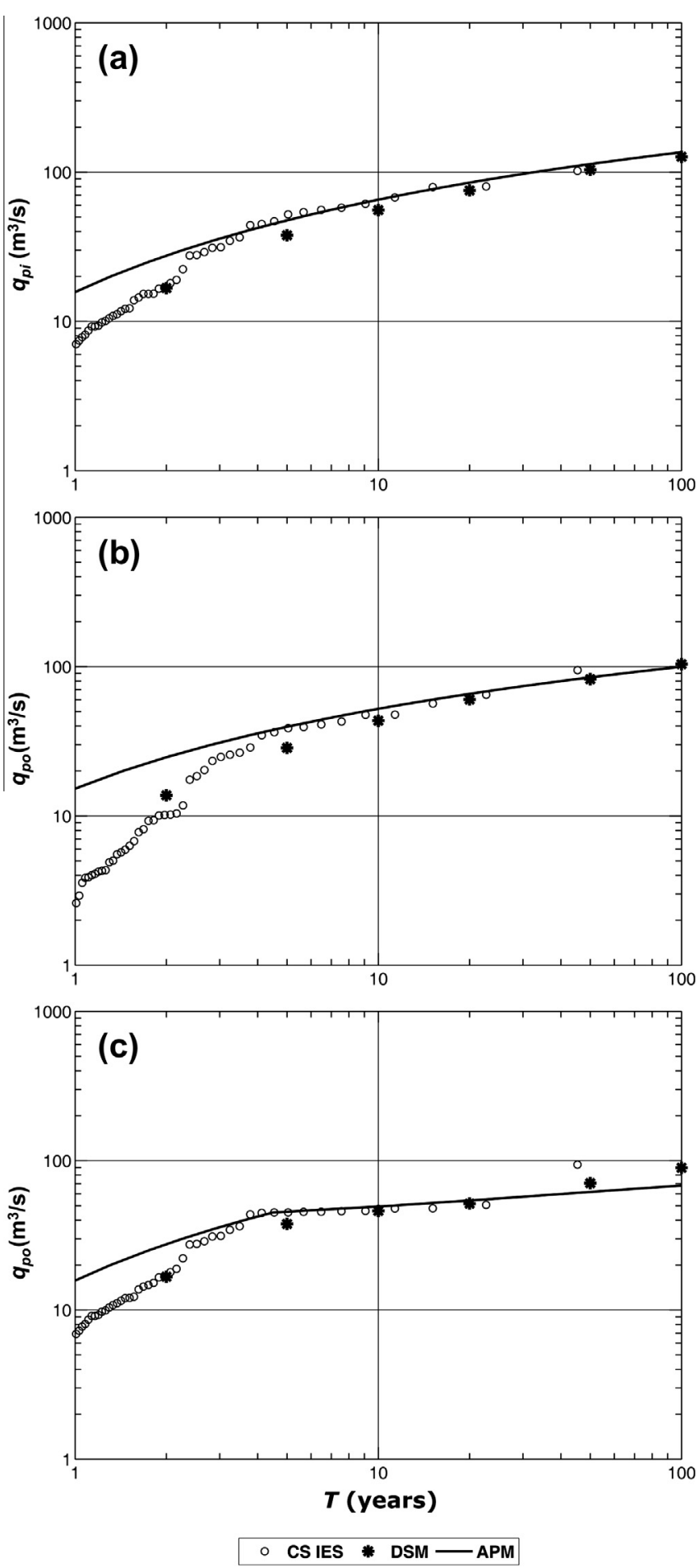

Fig. 5. Distributions of the peak inflow discharge (a), the peak outflow discharge for on line reservoirs (b) and the peak outflow discharge for off line reservoirs (c) (CS IES: continuous simulation individual event statistics, DSM: design storm method; APM: analytical-probabilistic method).

- Discrepancies between frequency distributions derived by continuous approaches for 1-2 year return periods may be partly explained by the incapability of a triangular hydrograph to suit the real flood patterns for very low flows, leading to a peak magnification. Deficiencies of exponential functions to represent rainfall variable distributions for minor events must play a role, as well.
- The definition of the storage constant introduces a linearization of the reservoir behaviour. This hypothesis holds in the analysed routing reservoirs because of the particular combination of the storage function, increasing according to a cubic relationship of the water stage, and of the discharge function, given by the combination of orifice and weir discharges. The relationship between volume and discharge is thus properly interpolated by a straight line, bearing a small overestimation of the discharged flow rate for medium-low water stages and a small underestimation for the largest ones. Evidently, polynomial relationships of higher order should be implemented in the model derivation when the real function is significantly non-linear.

- The weir hydraulics is not accounted for by the analytical-probabilistic model in the off-line reservoir situation. Assuming that the downstream discharge is equal to the threshold one, an overestimation of the spillway efficiency and, consequently, of the overall facility is expected. In the analysed case study such an error is however fairly small, thanks to the presence of a gate crossing the stream bed and a long weir, that ensure an efficiency improvement. Taking into account the maximum inflow peak discharge obtained from continuous simulations, that is $102 \mathrm{~m}^{3} / \mathrm{s}$ for a return period of 46 years, the real downstream discharge is greater than the threshold one by less than $12 \%$. Dealing with simple spillways, for which the efficiency is more rapidly changing, the choice of the threshold discharge value should be more carefully handled.

Finally, in all three cases, peak discharges derived by the design storm method prove to be realistic as well and, for a 2 year return period, they match continuous simulations better than the analytical-probabilistic curves do. Nevertheless, continuous simulations evidenced that AMC II, which was assumed for the hydrologic loss computation, is satisfied by only $20 \%$ of storms, while about $70 \%$ of them show dry condition AMC I and the remaining $10 \%$ wet condition AMC III. For more frequent rainfalls, the design storm method hence would generate runoff volumes larger than the real ones. On the other hand, actual wet weather durations are expected to be shorter than the wet weather duration of the design storm, set twice the time of concentration. Hence, mean intensities lower than those of observed storms are employed. These conflicting aspects evidently compensate each other.

\section{Conclusions}

Although relevant simplifications in the representation of the probabilistic precipitation structure and of the hydrological processes were exploited, effective analytical-probabilistic methods devoted to sizing on-line and off-line flood routing reservoirs were herein constructed. The study shows that their performance assessments are in satisfactory agreement with those of benchmarking continuous simulations for return periods greater than 5:10 years, so that the derived analytical functions represent valid alternatives to other approaches both for the on-line and for the off-line case.

It is important to underline that the model goodness was achieved through some significant improvements in the schematization of the hydraulic device behaviour, when the storage capacity is supplied either on-line or off-line. Moreover, since the model was tested with respect to a small-medium size natural watershed, the possibility of employing analytical-probabilistic methodologies is supported for hydrologic applications regarding fairly large spatial scales, in which a uniform spatial distribution of the precipitation may be a reasonable assumption.

When the discretization thresholds for the rainfall event identification are chosen according to parameters featuring the 
considered hydrologic-hydraulic phenomena, the proposed strategy appears to be efficacious in keeping the derived model as simple as possible and in isolating events that are actually independent. On one hand, the value of the initial abstraction IA allowed to generate floods having significant runoff volumes. On the other hand, the value of the interevent time definition IETD, equal to the catchment-reservoir response time, leads to a small probability of flood overlapping and, in practice, implies that the reservoir is empty for any floods. Nonetheless, the proposed model deserves further validation with respect to different climates and hydrological characteristics, especially in order to investigate both the performance assessment sensitivity with respect to other precipitation regimes and the opportunity to implement in the derivation procedure different rainfall-runoff transformation schemes suitable for various hydrological loss potentials. In this perspective, the comparison with observed long-term discharge series would definitely provide the best confirmation.

Further developments in the methodology would certainly derive by incorporating the observed dependence structure relating to input rainfall random variables and more suitable marginal distribution functions, such as the Weibull or the generalized Pareto [46] distributions. Unfortunately this would impose a numerical integration of the derived distribution functions, thereby losing the analytical formulation which is one of the main attractions for practical design purposes. It would however be interesting to quantify the eventual improvement in the effectiveness with respect to the present formulation.

Despite its pathologies, the design storm method surprisingly yielded outcomes matching the continuous simulation ones as well. For larger return periods (50:100 years and more), this could be due to the natural trend of extreme events to satisfy the approach assumptions. The frequency of occurrence of flood variables, such as runoff volume and peak discharge, tends to equal the ddf curve one, while other aspects, such as initial moisture conditions, wet weather durations and spatial patterns, are likely to be less determinant. Conversely, the goodness of the design storm method assessments for very low return periods (2:5 years) is more difficult to explain. This behaviour can be justified only as a compensation of errors, due to a favourable combination of arbitrary choices.

It could be argued that the same occurs in the analytical-probabilistic procedure herein discussed. Unlike the design storm method, in which the parameterization is guided by heuristic evaluations supported by design experience and liable to important site specific and application scale adaptations, in the analyticalprobabilistic procedure such choices rely on objective hydrological-hydraulic characteristics of the catchment-reservoir system.

According to other authors [16,31], even though realistic performance assessments can be achieved by means of the design storm approach, the exploitation of analytical-probabilistic methodologies should be preferred. They may be recommended in the engineering practice to face hydraulic design problems on various watershed scales, not only when quality issues are involved $[17,38]$, but also for purely quantitative runoff management. Unfortunately the real world application of analytical-probabilistic methodologies is generally made difficult by the lack of rainfall probability distribution parameters. Their extensive mapping, as already carried out in some countries [6], would be crucial in order to skip the discretization procedure, greatly enhancing the applicability and the attractiveness of these methodologies.

\section{References}

[1] Adams BJ, Howard CDD. Design storm pathology. Can Water Resour J 1986;11(3):49-55. http://dx.doi.org/10.4296/cwrj1103049.
[2] Adams BJ, Fraser HG, Howard CDD, Hanafy MS. Meteorological data analysis for drainage system design. J Environ Eng - ASCE 1986;112(5):827-48. http:/ dx.doi.org/10.1061/(ASCE)0733-9372(1986) 112:5(827).

[3] Adams BJ, Papa F. Urban stormwater management planning with analytical probabilistic models. New York, NY: John Wiley \& Sons; 2000.

[4] Akan AO. Detention pond sizing for multiple return periods. J Hydraul Eng ASCE 1989;115(5):650-64. http://dx.doi.org/10.1061/(ASCE)0733-9429(1989) $115: 5(650)$.

[5] Akan AO, Houghtalen RJ. Urban hydrology, hydraulics and stormwater quality. Hoboken, NJ: John Wiley \& Sons; 2003.

[6] American Society of Civil Engineers, Water Environmental Federation. Urban runoff quality management. Reston, VA: American Society of Civil Engineers; 1998.

[7] Andrés-Doménec I, Montanari A, Marco JB. Stochastic rainfall analysis for storm tank performance evaluation. Hydrol Earth Syst Sci 2010;14(7):1221-32. http://dx.doi.org/10.5194/hess-14-1221-2010.

[8] Bacchi B, Larcan E, Rosso R. Stima del fattore di attenuazione per la valutazione del colmo di piena prodotto da piogge efficaci di durata finita ed intensità costante. Ingegneria Sanitaria 1989:1:6-15.

[9] Bacchi B, Balistrocchi M, Grossi G. Proposal of a semi-probabilistic approach for storage facility design. Urban Water J 2008;5(3):195-208. http://dx.doi.org/ 10.1080/15730620801980723.

[10] Balistrocchi M, Grossi G, Bacchi B. An analytical probabilistic model of the quality efficiency of a sewer tank. Water Resour Res 2009;45. http:// dx.doi.org/10.1029/2009WR007822. W12420:1-12.

[11] Balistrocchi M, Bacchi B. Modelling the statistical dependence of rainfall event variables through copula functions. Hydrol Earth Syst Sci 2011;15(6):1959-77. http://dx.doi.org/10.5194/hess-15-1959-2011.

[12] Bocchiola D, Rosso R. Use of a derived distribution approach for flood prediction in poorly gauged basins: a case study in Italy. Adv Water Resour 2009;32(8):1284-96. http://dx.doi.org/10.1016/i.advwatres.2009.05.005.

[13] Bonta JV, Rao R. Factors affecting the identification of independent storm events. J Hydrol 1988;98(3-4):275-93. http://dx.doi.org/10.1016/00221694(88)90018-2.

[14] Burlando P, Rosso R. Scaling and multiscaling models of depth-durationfrequency curves for storm precipitation. J Hydrol 1996;186(1-2):45-64. http://dx.doi.org/10.1016/S0022-1694(96)03086-7.

[15] Brath A, Fiorentino M, Villani P. Stochastic and geomorphological models for flood volumes estimation. In: Proceedings of the 6th IAHR international symposium on stochastic hydraulics, Taipei, TW. 1992.

[16] Chen J, Adams BJ. Analysis of storage facilities for urban stormwater quantity control. Adv Water Resour 2005;28(4):377-92. http://dx.doi.org/10.1016/ j.advwatres.2004.11.005.

[17] Chen J, Adams BJ. Urban stormwater quality control analysis with detention ponds. Water Environ Res 2006;78(7):744-53. http://dx.doi.org/10.2175/ $106143005 \times 72939$.

[18] Chow VT, Maidment DR, Mays LW. Applied hydrology. Singapore, SG: McGraw-Hill; 1988.

[19] Cordova JR, Rodriguez-Iturbe I. On the probabilistic structure of storm surface runoff. Water Resour Res 1985;21(5):755-63. http://dx.doi.org/10.1029/ WR021i005p00755.

[20] De Michele C, Salvadori G. On the derived flood frequency distribution: analytical formulation and the influence of antecedent soil moisture condition. J Hydrol 2002;262(1-4):245-58. http://dx.doi.org/10.1016/S0022-1694(02) 00025-2.

[21] De Michele C, Salvadori G, Canossi M, Petaccia A, Rosso R. Bivariate statistical approach to check adequacy of dam spillway. J Hydrol Eng 2005;10(1):50-7. http://dx.doi.org/10.1061/(ASCE)1084-0699(2005) 10:1(50).

[22] Diaz-Granados MA, Valdes JB, Bras RL. A physically based flood frequency distribution. Water Resour Res 1984;20(7):995-1002. http://dx.doi.org/ 10.1029/WR020i007p00995.

[23] Dunkerley D. Identifying individual rain events from pluviograph records: a review with analysis of data from an Australian dryland site. Hydrol Process 2008;22(26):5024-36. http://dx.doi.org/10.1002/hyp.7122.

[24] Eagleson SP. Dynamics of flood frequency. Water Resour Res 1972;8(4): 878-98. http://dx.doi.org/10.1029/WR008i004p00878.

[25] European Parliament and Council. Directive 2007/60/EC on the assessment and the management of flood risks. 2007.

[26] Franchini M, Galeati G, Lolli M. Comparative analysis of some methods for deriving the expected flood reduction curve in the frequency domain. J Hydrol 2005;303(1-4):1-15. http://dx.doi.org/10.1016/i.jhydrol.2004.07.008.

[27] Giandotti M. Previsione delle piene e delle magre dei corsi d'acqua. Rome, IT: Ministero dei Lavori Pubblici, Servizio Idrografico Italiano; 1934.

[28] Goel NK, Seth SM, Chandra S. Multivariate modeling of flood flows. J Hydraul Eng - ASCE 1998;124(2):146-55. http://dx.doi.org/10.1061/(ASCE)07339429(1998) 124:2(146).

[29] Gottardi G, Maglionico M. Analisi del metodo dell'invaso per il dimensionamento degli invasi di laminazione a servizio delle reti di drenaggio urbano. In: Proceedings of the XXXI national conference on hydraulics and hydraulic constructions. University of Perugia, Perugia, IT. 2008.

[30] Guo Y, Adams BJ. Hydrologic analysis of urban catchments with event-based probabilistic models: 2. Peak discharge rate. Water Resour Res 1998;34(12):3433-43. http://dx.doi.org/10.1029/98WR02448. 
[31] Guo Y, Adams BJ. An analytical probabilistic approach to sizing flood control detention facilities. Water Resour Res 1999;35(8):2457-68. http://dx.doi.org/ 10.1029/1999WR900125.

[32] Hong Y-M. Graphical estimation of detention pond volume for rainfall of short duration. J Hydro-environ Res 2008;2(2):109-17. http://dx.doi.org/10.1016 j.jher.2008.06.003.

[33] Kao SC, Govindaraju RS. A bivariate frequency analysis of extreme rainfall with implications for design. J Geophys Res 2007;112(D13119):1-15. http:/l dx.doi.org/10.1029/2007/D008522.

[34] Krstanovic PF, Singh VP. A multivariate stochastic flood analysis using entropy. In: Singh VP, editor. Hydrologic frequency modelling. Dordrecht, NL: Reidel; 1987. p. 515-39.

[35] Lynch JA, Corbett ES, Sopper WE. Effects of the antecedent soil moisture on stormflow volumes and timing. In: Beven KJ, editor. Streamflow generation processes. Benchmark papers in hydrology, 1. Wallingford, UK: International Association of Hydrological Sciences (IAHS), 2006. p. 324-35.

[36] Majone U, Mignosa P, Tomirotti M. Application of the Synthetic Hydrograph Method to Some Case Studies. In: Proceedings of the 32nd congress of IAHR. Venice, IT. 2007.

[37] Mambretti S. Metodi pratici per il dimensionamento delle vasche di laminazione in ambiente urbano. Milan (IT): Milan Polytechnic; 1991.

[38] Marsalek J. Synthesized and historical storms for urban drainage design. In: Proceedings of the 1 st international conference on urban storm drainage. University of Southampton, Chichester, UK. 1978.

[39] Mishra SK, Singh VP. Long-term hydrological simulation based on the Soil Conservation Service curve number. Hydrol Process 2004;18(7):1291-313. http://dx.doi.org/10.1002/hyp.1344.

[40] Moisello U, Papiri S. Relazione tra altezza di pioggia puntuale e ragguagliata. In: Proceedings of the XXVIII national conference on hydraulics and hydraulic constructions. Padua, IT. 1986.

[41] Nash JE. The form of the instantaneous unit hydrograph. IAHS Publ 1957;45(34):114-21.

[42] Papiri S, Moncalvo M, Valcher P. Sul dimensionamento idraulico delle vasche volano a servizio delle reti di drenaggio urbano. In: Proceedings of the conference in memory of Carlo Cao. University of Cagliari, Cagliari, IT. 1998.
[43] Quader A, Guo Y. Peak discharge estimation using analytical probabilistic and design storm approaches. J Hydrol Eng 2006;11(1):46-54. http://dx.doi.org 10.1061/(ASCE)1084-0699(2006) 11:1(46).

[44] Ranzi R, Mariani M, Rossini E, Bacchi B. Analisi e sintesi delle piogge intense del territorio bresciano. Brescia (IT): DICATAM, University of Brescia; 1999. Technical, Report no. 12.

[45] Restrepo-Posada PJ, Eagleson PS. Identification of independent rainstorms. J Hydrol 1982;55(1-4):303-19. http://dx.doi.org/10.1016/0022-1694(82) 90136-6.

[46] Salvadori G, De Michele C. Statistical characterization of temporal structure of storms. Adv Water Resour 2006;29(6):827-42. http://dx.doi.org/10.1016 j.advwatres.2005.07.013.

[47] Sivapalan M, Wood EF, Beven KJ. On hydrologic similarity 3, a dimensionless flood frequency model using a generalized geomorphic unit hydrograph and partial area runoff generation. Water Resour Res 1990;26(1):43-58. http:/ dx.doi.org/10.1029/WR026i001p00043.

[48] Urbonas BR, Stahre P. Stormwater best management practices and detention for water quality, drainage and CSO management. Englewood Cliffs NJ: Prentice Hall; 1993.

[49] Urbonas BR, Doerfer JT. Master planning for stream protection in urban watersheds. Water Sci Technol 2005;51(2):239-47.

[50] US Environmental Protection Agency. Low impact development (LID), a literature review (EPA-841-B-00-005). Washington, DC: US Environmental Protection Agency, Office of Water; 2000.

[51] US Soil Conservation Service. Urban hydrology for small watershed, tech. rep. n. 55. Washington: US Department of Agriculture; 1975.

[52] Walesh SG. Urban surface water management. New York, NY: John Wiley \& Sons; 1989.

[53] Wycoff RL, Singh UP. Preliminary hydrologic design of small flood detention reservoirs. Water Resour Bull 1976;12(2):337-49.

[54] Yue S. The bivariate lognormal distribution to model a multivariate flood episode. Hydrol Process 2000;14(14):575-88. http://dx.doi.org/10.1002/10991085(20001015)14:14<2575::AID-HYP115>3.0.CO;2-L. 